\title{
Use of Coca-Cola drinks in gastric pathology in pediatric patients
}

\author{
Cristina Munteanu
}

Pediatric Department, "Victor Babes" University of Medicine and Pharmacy, Timisoara, Romania

\begin{abstract}
Facing us the relatively frequent tendency of many people - medical professionals or not - to administer Coca-Colatype carbonated beverages in the case of nausea-type gastric symptoms or vomiting in pediatric or adult patients, we have tried to investigate whether there is a scientific basis for this practice. The phosphoric acid present in this beverage is found in over the counter products (OTC), recommended in the case of nausea and vomiting. On the other hand, the medical literature cites studies in which this type of beverage has been used in the treatment of gastric or intestinal bezoars, fecalomas or even in some cases of gastric reflux or gastroparesis. One of the studies analyzed reveals the antibacterial effect of this type of beverage, on bacteria such as Bacillus cereus, Enterococcus faecalis, Escherichia coli, Escherichia coli O:157 H:7, Salmonella enteritidis, Yersinia enterocolitica.

We expect more studies to be carried out on the anti-emetic and antimicrobial therapeutic efficacy of this drink and to balance the positive versus negative effects in its use in children.
\end{abstract}

Keywords: nausea, vomiting, antiemetic, phosphoric acid, Coca-Cola

\section{INTRODUCTION}

The pediatric pathology in which symptoms of nausea are being experienced, whether or not accompanied by vomiting, meteorism, eructation, abdominal pain, diarrhoea or constipation, etc. is extremely varied and includes a wide range of conditions, acute or chronic, with varying degrees of severity.

These conditions may be in the field of gastric pathology, but there are many other conditions that may start with symptoms of this type in the pediatric patient. Thus, these symptoms can be seen in food or drug poisoning, in various food intolerances and allergies, in gastroenteritis of viral origin, gastro-oesophageal reflux disease, hiatal hernia, hypertrophic pyloric stenosis (with the particularity of the onset after the first and the third week of life up to 5 months in cases with late onset) (1), inflammatory bowel disease, biliary lithiasis, pancreatitis, appendicitis, intestinal occlusion, abdominal migraine, cyclical vomiting, etc. From the range of other pathologies we mention the renal, hepatic, neurological disorders, those from the ENT field, parasites, metabolic or endocrine disturbances, cranial trauma, stress etc.
Depending on the etiology of these conditions the treatment will also be different (dietary, medical, surgical, psychotherapeutic). When a child experiences nausea and vomiting that cannot be stopped by fasting and the gradual and correct re-hydration and feeding, the parent should immediately seek medical help.

\section{OBJECTIVES}

The aim of the present research was to identify an objective link between the consumption of Coca-Cola drinks and the antiemetic effect.

This is because at present there is a tendency quite common in the general population to administer to children with nausea and vomiting drinks such as Coca-Cola, Pepsi, Fanta, Sprite. This practice is even recommended by some healthcare professionals.

\section{MATERIALS AND METHODS}

We have therefore researched the Pubmed and Google Academic electronic database of 2007-2019 looking for articles that refer to the existence of a link 
between the consumption of carbonated beverages (especially those of the Coca-Cola type) and their antiemetic effect.

We did not identify studies strictly related to this aspect, but studies were found on the use of Coca-Cola in other gastric pathologies, a study that certifies the antibacterial effect of this type of drink and a study that analyzes and compares the osmolarity and electrolyte content of Cola drinks versus rehydration solutions.

\section{DISCUSSIONS}

Coke type beverages stimulate intestinal peristalsis. Studies have also been performed regarding its administration with positive effects in the case of gastroparesis (2), gastric and intestinal bezoars (3-10), intestinal faecal impaction (11) and even in the gastrointestinal reflux (12). Also, some studies show that this type of beverage causes the increase of bicarbonate at the gastric and duodenal levels, most probably in relation to the acidic $\mathrm{pH}$ of the solution (13).

However, we are concerned whether there is a connection between the consumption of this beverage and a possible antiemetic effect. Thus we continued the research by studying the labels of these products (Coca-Cola, Pepsi-Cola, Sprite, Fanta) to see what the manufacturer declares as entering into their composition. There is no specific common ingredient for these products that can guide us in our efforts (the ingredients common to all are water, sugar, carbon dioxide). However, we noticed a common ingredient for CocaCola and Pepsi-Cola drinks, namely: phosphoric acid and a common ingredient for Fanta and Sprite drinks, namely: citric acid.

These two substances - the phosphoric acid and the citric acid - are substances cited in the pharmacology literature as having an antiemetic role and being used in the preparation of effervescent (gaseous) and non-greasy lemonade (14) and being recognized as having a laxative, purgative, antiemetic, tonic or revitalizing role, also recommended in febrile conditions or intoxication. Thus, the 10th edition of the Romanian Pharmacopoeia presents the official recipes (15) of gaseous lemonade for the Riviere solution and the non-lemonade solution of the magnesium citrate solution, known as the Roge Purgative Lemonade (16).

With the chemical formula $\mathrm{H}_{3} \mathrm{PO}_{4}$, the phosphoric acid appears on the list of food additives as E338 and its use as an additive for food consumed by children is allowed. Citric acid, having the chemical formula $\mathrm{C}_{6} \mathrm{H}_{8} \mathrm{O}_{7}$, appears on the previously mentioned list as E330. It is used as an additive for the role of flavor enhancer or preservative, inhibiting the development of certain microorganisms.
The literature mentions the recommendation of the administration of phosphoric acid solution (17) to athletes who have nausea, but have not vomitted and do not have fever.

Phosphoric acid enters the composition of some OTC drugs such as Emetrol, Nausetrol, Emecheck, Formula EM, which are recommended for the relief of gastric problems associated with nausea and vomiting. All of these products contain dextrose, fructose and phosphoric acid.

A study conducted by a group of researchers in Turkey on three brands of Coca-Cola revealed a strong antibacterial effect on the following types of bacteria: Bacillus cereus, Enterococcus faecalis, Escherichia coli, Escherichia coli O:157 H:7, Salmonella enteritidis, Yersinia enterocolitica (18).

Other researches conducted on the administration of Cola drinks in gastric pathologies with diarrhea aimed to prove whether this drink, consumed as such or from which carbon dioxide is removed ("flat"), can prevent dehydration and could thus replace rehydration solutions for children suffering from fluid loss (19). Research has taken into account the value of osmolarity and the electrolyte content of rehydration solutions compared to fizzy drinks of the Cola type.

In conclusion, can we administer Coca-Cola type beverages to a child who is vomiting?

Is the amount of phosphoric acid in this drink sufficient to ensure the antiemetic therapeutic effect?

The manufacturer does not specify on the label the amount of phosphoric acid contained by the beverage. From the research we have found that Cola drinks contain approximately $480-530 \mathrm{mg}$ phosphoric acid/1 Coca-Cola drink (20). With a simple calculation, we reach an average of $2.5 \mathrm{mg}$ phosphoric acid per $5 \mathrm{ml}$ Cola drink. OTC products containing phosphoric acid, used for the antiemetic effect, contain a greater quantity of phosphoric acid $/ 5 \mathrm{ml}$. Thus, the product called Emetrol contains $21.5 \mathrm{mg} / 5 \mathrm{ml}$, the recommendation for administration in children is $5-10 \mathrm{ml}$, with the possibility of repetition after 15 minutes from the first administration. It remains to be investigated if we can get the antiemetic effect at $2.5 \mathrm{mg} / 5 \mathrm{ml}$, the average amount of phosphoric acid per $5 \mathrm{ml}$ Cola drink.

On the other hand, the antibacterial effect of this drink - proven by the study cited above - could be the basis for its use in the conditions of nausea and vomiting that occur in food poisoning and in gastroenterocolitis of various etiologies.

Cola drinks have an osmolarity between 469 $\mathrm{mmol} / \mathrm{l}$ and $656 \mathrm{mmol} / \mathrm{l}$, which represents a high osmolarity compared to that of the rehydration solutions approved by the WHO. Also, their concentration in electrolytes is very low compared to rehydration solu- 
tions. The conclusion of the analyzed study was that Cola drinks should not be recommended as rehydration solutions in acute diarrhea in general or in children, in particular (19).

We also need to put in the balance the effect of caffeine, which will stimulate the child and especially the stimulation of the taste for sweets and for carbonated drinks, which is not beneficial in the long run. Obviously, the child will receive a small amount, one teaspoon / one swallow; a small amount does not pose the problem of affecting the phospho-calcium metabolism or osteoporosis, enamel erosions, but the stimulation of the taste for such drinks from an early age can give birth to the big consumers of carbonated drinks of tomorrow, with long term negative effects.

\section{CONCLUSIONS}

Classic allopathic antiemetic treatments most often have adverse effects such as extrapyramidal manifestations and allergic reactions, so that using less typical or conventional methods, which are not related to the medical routine, is a tempting fact, common in the population. Sometimes practices are harmless, sometimes they can endanger the lives of those who

\section{REFERENCES}

1. Nelson. Textbook of pediatrics. 18th edition: Saunders Elsevier. 2007:1555.

2. Oberbaum $M$, Schmell $M$, Schreiber $R$ et al. "Do two walk together unless they have agreed to do so?" - Combining conventional and complementary medicine in the treatment of gastroparesis. Harefuah. 2015 Jan;154(1):31-4, 68.

3. Ladas SD, Kamberoglou D, Karamanolis $G$ et al. Systematic review: Coca-Cola can effectively dissolve gastric phytobezoars as a first-line treatment. Aliment Pharmacol Ther. 2013 Jan;37(2):169-73.

4. Murrilo-Matamoros C, Ferri-Bataller R, Muñiz-Muñoz M et al. Giant gastric phytobezoar secondary to pyloric stenosis treated with Coca-Cola®: A case report. Semergen. 2019 Jan - Feb;45(1):e3-e5.

5. Cerezo Ruiz A, Domíniguez Jiménez JL, Uceda-Vaño. Cellulase, Coca-Cola ${ }^{\circledR}$, pancreatin and ursodeoxycholic acid in the dissolution of gastric bezoars: Why not all together? Rev Esp Enferm Dig. 2018 Jul;110(7):472-473.

6. Yamazato Y, Kosuga T, Ichikawa D et al. A Case of Intestinal Obstruction Caused by a Bezoar after Pylous-Preserving Gastrectomy. Gan To Kagaku Ryoho. 2017 Nov;44(12):1269-1271.

7. Endo K, Kakisaka K, Suzuki Y et al. Obstructive Bezoars of the Small Bowel Treated with Coca-Cola Zero through a Long Intestinal Tube and Endoscopic Manipulation. Intern Med. 2017 Nov 15;56(22):30193022.

8. Nelson A, Romo N, Levanon D et al. Gastric Bezoar Treatment Using Oral Coca-Cola. Clin Pediatr (Phila). 2017 May;56(5):485-487.

9. Stathis $P$, Tzias V, Argyris $P$ et al. Gastric bezoar complication of Duodopa $\left({ }^{\circledR}\right)$ therapy in Parkinson's disease, treated with CocaCola(®).Mov Disord. 2014 Jul;29(8):1087-8. test them on their own skin or on their children. Often these practices are encouraged by some healthcare professionals. This is also the case with the indication of administering Coca-Cola to children in nausea and vomiting. Although medicine has evolved, sometimes we can resort to less conventional methods with proven therapeutic effects in situations where we do not have access to a doctor and specific medication. In this case we could benefit from the anti-emetic effect (through its phosphoric acid content) and antibacterial effect of this type of drink. The main correct medical recommendation is to see a doctor and receive appropriate treatment, following the identification of the cause of vomiting.

We also expect the carrying out of studies in what regards the certain antiemetic role of these popular drinks and the expansion of the research regarding their antimicrobial and antiviral potential in gastroenterocolitis and intestinal virosis, weighing the positive and negative effects (on the short and long term) in order to give a pertinent answer to this problem and in what regards the safety of using Cola beverages in the case of nausea and vomiting in pediatric patients and beyond.

Conflict of interest: none declared Financial support: none declared

10. Lu L, Zhang XF. Gastric Outlet Obstruction-An Unexpected Complication during Coca-Cola Therapy for a Gastric Bezoar: A Case Report and Literature Review. Intern Med. 2016;55(9):1085-9.

11. Ontanilla Clavijo G, León Montañés R, Sánchez Torrijos $Y$ et al. Colonic obstruction secondary to sigmoid fecaloma endoscopically resolved with Coca-Cola®. Rev Esp Enferm Dig. 2017 Apr; 109(4):306-308.

12. Gupta E, Hartronft S, Prange M. Coca-cola: A new therapy for reflux. J Am Geriatr Soc. 2009 Feb;57(2):364-5.

13. Sasaki Y, Aihara E, Ise F et al. Stimulatory effect of Coca-Cola on gastroduodenal HCO3- secretion in rats. Inflammopharmacology. 2007 Oct;15(5):223-8.

14. https://www.scoalacantemir.ro/files/uploads/Forme_farmaceutice_ca_ sisteme_disperse_omogene.pdf.

15. Farmacopeea Română, ed. a X-a. Bucureşti: Ed. Medicală, 1998:859-860; 867-868.

16. Vicaş LG. Tehnică farmaceutică, Ed. Universităţii din Oradea, 2006:63.

17. Cuppett M, Walsh K. General Medical Conditions in the Athlete. Second edition: Elsevier Mosby, 2012:184.

18. Dağ Ş, Özpinar H, Sari M et al. Antimicrobial Effect of Cola on Several Microorganisms. Cumhuriyet Science Journal. 2015; 36 (1):52-59.

19. M Jacobs, A Reece. Does drinking "flat" cola prevent dehydration in children with acute gastroenteritis? Archives of Disease in Childhood - Education and Practice. 2008;93:129-131.

20. Bello MA, Gustavo González A. Determination of Phosphate in Cola Beverages Using Nonsuppressed Ion Chromatography. Journal of Chemical Education. 1996, 73, 12:1174. 